Sean Crawford*

\title{
Brandom and Quine on Perspectivally Hybrid De Re Attitude Ascription: A Solution to a Problem in the Explanation of Action
}

\author{
https://doi.org/10.1515/jtph-2020-0004
}

Published online August 9, 2021

\begin{abstract}
In Making it Explicit Robert Brandom claims that perspectivally hybrid de re attitude ascriptions explain what an agent actually did, from the point of view of the ascriber, whether or not that was what the agent intended to do. There is a well-known problem, however, first brought to attention by Quine, but curiously ignored by Brandom, that threatens to undermine the role of de re ascriptions in the explanation of action, a problem that stems directly from the fact that, unlike de dicto ascriptions, they permit the attribution of inconsistent attitudes to agents. I propose a solution to the problem which I believe is consistent with Brandom's approach to the nature of intentionality and the explanation of action.
\end{abstract}

Keywords: de re attitude ascription, action explanation, Robert Brandom, belief fragmentation, W. V. Quine

\section{De re and de dicto: Brandom and Quine on Hybrid Perspectivality}

The social-inferentialist normative pragmatics of Robert Brandom's Making it Explicit (Brandom 1994-MIE hereafter) culminates in a final chapter that presents a powerful account of the nature of propositional attitude attribution, in particular belief ascription. ${ }^{1}$ De re and de dicto attitude ascriptions are the core elements of this account, figuring centrally in his inferentialist explanation of the representational aspect of propositional content, in which its socially perspectival character forms the basis for his theory of the explanation and assessment of intentional action.

1 Some elements of the account are recapitulated briefly and less technically in ch. 5 of Articulating Reasons (Brandom 2000, cited hereafter as $A R$ ).

*Corresponding author: Sean Crawford, Philosophy, The University of Manchester, Oxford Road, Manchester M13 9PL, UK, E-mail: sean.crawford@manchester.ac.uk. https://orcid.org/00000002-3110-0210

2 Open Access. ( 2021 Sean Crawford, published by De Gruyter. (cc)BY the Creative Commons Attribution 4.0 International License. 
Brandom's chief thesis is that “de re ascriptions are the fundamental representational locution of natural languages" (MIE, p. 499), because they say what beliefs and other propositional attitudes are about, what they represent, what they are true of-from the perspective of the ascriber, a perspective that might, importantly, be disavowed by the subject of the ascription. As applied to intentional action, the claim is that de re ascriptions explain what an agent actually did, from the point of view of the ascriber, whether or not that was what the agent intended to do. There is a well-known problem, however, curiously ignored by Brandom, that threatens to undermine the role of de re ascriptions in the explanation of action, a problem that stems directly from the fact that, unlike de dicto ascriptions, they permit the attribution of inconsistent contents to agents. I propose a solution which I believe is consistent with Brandom's ineliminably normative social-inferential approach to meaning and intentionality.

As Brandom notes (MIE, p. 500), philosophical tradition distinguishes two different styles or readings of propositional attitude attribution, de dicto ones and de re ones. As the Latin terms indicate, de dicto ascriptions attribute belief in-or, in Brandom's preferred normative terminology, doxastic commitment to-a dictum or saying or proposition, whereas de re ascriptions attribute belief about a res or object. Canonically speaking, using Brandom's regimentation, the dictum or proposition believed in a de dicto ascription is reported by a 'that'-clause, while in a de re ascription the res or object of belief is singled out with an 'of'-phrase. Schematically, where $t$ is singular term and $\phi$ is a predicate, one believes de dicto that $\underline{t} \underline{\text { is } \phi}$ and believes de re, of $\underline{t}$, that it is $\phi$. For example,

DD Adams believes (de dicto) that the inventor of bifocals did not invent the lightening rod.

DR Adams believes (de re), of the inventor of bifocals, that he did not invent the lightening rod. $^{2}$

2 The examples are adapted from Brandom. Note that for reasons having to do with anaphor playing a systematic role in Brandom's expressivist inferential-substitutional account of semantic notions, such as truth, reference and representation (see especially MIE, ch. 7), Brandom's regimentation of de re ascriptions employs anaphoric cross-reference: the content-specifying term is "exported" to the wide scope of 'of' leaving behind an ascription-structural anaphoric dependent, usually a pronoun, lying within the narrow scope of 'that'. But there are other ways of regimenting de re ascriptions that do not employ anaphoric cross-reference between terms in 'of' and 'that' positions. DR can be phrased, for example, using infinitival constructions such as: 'The inventor of bifocals is believed by Adams to have invented the lightning rod' or 'The inventor of bifocals has the property of being believed by Adams to have invented the lightning rod'. Quine often uses infinitival forms. Perhaps this is because they are more naturally read as undertaking an ontological commitment on the part of the ascriber to the existence of the res. This is something that Brandom (mistakenly, in my view) rejects: according to him, aside from epistemically strong de re ascriptions of object-dependent de re beliefs (MIE, ch. 8, §5), which are ontologically committing, 
But 'that' and 'of' do not merely serve to indicate, respectively, which proposition is believed, in the de dicto case, and which object a belief is about, in the de re case. They also serve-and this is the fundamental point of utmost importance for Brandom - to mark an absolutely crucial distinction between the perspective of the believer-what his doxastic commitments are-and that of the ascriber-what her doxastic commitments are. More accurately, as we will see, it is the de dicto and de re "portions" of de re ascriptions that reveal the essentially perspectival character of propositional content. This is why de re ascriptions, rather than de dicto ones, are the primary representational locution (as one can see from DR above, Brandom-style de re ascriptions, unlike de dicto ones, actually contain both 'that'-clauses and 'of'-phrases). For the socially perspectival distinctions they mark form the very foundation for the deontic score-keeping intended to keep track of the various deontic statuses-the doxastic, substitutional, practical and other commitments and entitlements-involved in the kind of mutual understanding and communication central to rational discourse and the explanation of rational action so distinctive of sapient creatures.

Importantly, for Brandom, de dicto and de re do not serve to mark different kinds of beliefs; rather, they mark different kinds of ascriptions in which the same belief content or commitment is specified in different ways. A de dicto ascription reports what the believer believes in a way that he would acknowledge as what he believes. In Brandomese, it reports what the believer takes himself to be committed to. This acknowledged commitment is what is reported in the 'that'-clause of the belief ascription. I believe this idea is best expressed by saying that the believer accepts (or would accept, or is disposed to accept) the sentence (dictum) used to report the content of his belief, that is, the 'that'-clause. For instance, DD is warranted only if the ascriber undertakes the commitment that Adams is committed to accepting (or assenting to) the sentence 'The inventor of bifocals did not invent the lightening rod'-in other words, the ascriber must hold that Adams believes that the 'that'-clause is true. This is why the 'that'-clauses of de dicto ascriptions are by definition referentially opaque in Quine's (1956) sense: co-referring expressions

de re ascriptions do not commit the ascriber to the existence of the res. For Brandom (but not for Quine and not, I think, for most philosophers) it can be true that Ralph believes, of Pegasus, that he has wings, and that he believes, of Vulcan, that it is a planet. To my ear, ontological noncommitment is less plausible in 'Pegasus has the property of being believed by Ralph to have wings'. But this issue turns on further difficult matters, such as whether an object can have a relational property involving an existing thing without itself existing, issues orthogonal to those under discussion here. See also note 6 below. 
cannot necessarily be substituted salva veritate. We cannot necessarily substitute 'Benjamin Franklin' for 'the inventor of bifocals' in DD because Adams may well not accept (or may even reject) the sentence 'Benjamin Franklin did not invent the lightening rod', not realizing (or even denying) that Franklin is the inventor of bifocals.

A de re ascription, however, freely characterizes what is believed in terms that the believer may not recognize as something he believes, as something he is committed to. So, unlike DD, DR can be true even if Adams does not accept the sentence 'The inventor of bifocals did not invent the lightening rod'. He might not accept this sentence because he accepts the contradictory sentence 'The inventor of bifocals did invent the lightening rod'. Imagine, however, as before, that Adams does not realize that Benjamin Franklin invented bifocals. Perhaps he even believes (de dicto) that Franklin did not invent them. Suppose further that Adams does believe (de dicto) that Franklin did not invent the lightening rod. If the ascriber is committed to the claim that Franklin is the inventor of bifocals, then DR is warranted. Indeed, any de re ascription formed from DR by substituting a singular term co-referential with 'The inventor of bifocals' is warranted. De re ascriptions are, in Quine's sense, referentially transparent: co-referring expressions are substitutable salva veritate.

Brandom highlights a further essential feature of de re ascriptions, briefly alluded to already, namely, that they contain a de dicto 'that'-clause part in addition to their overall de re 'of' form. De dicto ascriptions, by contrast, are purely de dicto. What this means is that while de dicto ascriptions characterize reality from the point of view of the believer, de re ascriptions characterize reality from the point of view of both the ascriber and the believer. And that is the sense in which they have a perspectival character: they report (a part of) the ascriber's perspective on the world and (a part of) the believer's perspective on the world in one overall attribution. More specifically, in a de re attribution, the ascriber himself refers to some object in reality, other than the believer, and then says what the believer believes about that object. In short, as Brandom concisely summarizes it, de re specifications of conceptual content express "hybrid deontic attitudes" (MIE, p. 529).

This hybrid feature of de re ascriptions was emphasized by Quine several decades after his classic 1956 paper 'Quantifiers and Propositional Attitudes', which inaugurated modern discussion of the de dicto/de re distinction. In that original paper Quine is concerned primarily with finding a (first order) logical symbolization of quantified attitude attributions that ascribe what he called relational attitudes, such as 'There is someone whom Adams believes to have invented the lightening rod', without (by his lights) incoherently quantifying into a 
substitution-resistant and therefore referentially opaque position. ${ }^{3}$ Quine illustrates the problem with his famous story of Ralph and Ortcutt. Ralph has seen a suspicious character in a brown hat lurking near a "sensitive installation" who he thinks he is a spy. Ralph has also seen a grey-haired man at the beach who he thinks is a pillar of the community and is known to him as 'Bernard J. Ortcutt'. Unbeknownst to Ralph, Ortcutt is both pillar and spy. Given this identity, Quine then asks whether we can say of this man, Ortcutt himself, that Ralph believes him to be a spy. For reasons that need not detain us here, a Yes answer was deemed problematic by Quine. ${ }^{4}$ However, he admitted that we needed to be able to say this, so he proposed a technical means for doing so that avoided the initial (alleged) problems. Again, the details of the technical solution need not detain us here; we need only note that Quine originally accepted the coherence of de re ascriptions, such as

Ralph believes, of Ortcutt, that he is a spy.

At this time, however, he did not make much of their hybrid perspectival character. This came later. In Pursuit of Truth (1990) he begins by saying that in de dicto ascriptions, the 'that'-clauses (more accurately, his linguisticized versions of them) "mark an opaque interface between two ontologies, two worlds: that of the man in the attitude, however benighted, and that of our responsible ascriber of the attitude” (pp. 69-70). He then goes on to say that in de re ascriptions

The interface is sometimes breached. Like an actor stepping out of his part and speaking for himself, the ascriber is heard to say of the real people of his world that

(1) There are some whom Ralph believes to be spies, and not just that

(2) Ralph believes ' $\exists x(x$ is a spy)’. (loc. cit.)

Quines continues by noting that “In affirming (1) we dissociate Ralph's suspicions from the world as he conceives it and train them upon denizens of our real world; we ride roughshod over failures of identification." Similar remarks occur in the slightly later work From Stimulus to Science Quine (1995) where we find him saying

3 Quine's well-known general thesis that 'a position that resists substitutivity of identity cannot meaningfully be quantified' (1986a, p. 291) has been criticized by Kaplan (1986). As Forbes (1996) has persuasively argued, however, 'the cautious version of [Quine's thesis] claims only that there is a certain range of cases of substitution failure that involve a mechanism incompatible with quantifying in' and that 'The puzzle is that although attitude ascriptions seem on general grounds to belong to this range ... we have the particular example of ['There is someone whom Adams believes to have invented the lightening rod'] to indicate otherwise' (p. 338).

4 For the details, see Quine (1956), Kaplan $(1968,1986)$ and Crawford (2008). 
that the 'that'-clause "marks the boundary between the ascriber's impersonation of the attitudinist and the ascriber's speaking for himself” (p. 96), going on to note that

Now and again, however, the ascriber interrupts his empathy and interjects reality, by his own lights, into the attitudinist's world. He says there is someone whom Ralph believes to be a spy; someone in the ascriber's real world, irrespective of how Ralph's attitudinal world may be populated. ... Ascriptions such as (1), which breach the barrier between the ascriber's real world and the fancied world of the attitudinist, are called ascriptions of propositional attitude de re. The others are de dicto.

Under the influence of Robert Sleigh, Saul Kripke and David Kaplan, however, Quine eventually came to view de re ascriptions as highly problematic. This was because he took de re ascriptions to imply that the believer is acquainted or en rapport with the res-or "knows who" the res is-and he thought these epistemic notions were ineliminably context-dependent and therefore not scientifically respectable. ${ }^{5}$ Whereas Quine takes a dim view of de re ascriptions, thinking them unsuitable for serious science, and advocates instead what he takes to be a context-independent and scientifically respectable linguisticized version of de dicto ascriptions, Brandom views the barrier breach-the hybrid perspectivality-characteristic of de re ascriptions as precisely what makes them the suitable cornerstone for an irreducibly normative score-keeping practice of attributing and acknowledging deontic statuses, in particular doxastic and practical commitments.

In any propositional attitude ascription there is always a commitment attributed and one undertaken. In a de dicto ascription, a doxastic commitment is attributed to the believer, or "attitudinist" in Quine's parlance, by the 'that'-clause of the ascription. But since the whole ascription is a claim by the ascriber, the ascriber undertakes the commitment that the ascription is true (of course, the ascriber may also share the believer's commitment too but this is not something communicated in the ascription itself). ${ }^{6}$

5 I agree with Brandom that this is a mistake based on not distinguishing between epistemically strong de re ascriptions, involving demonstrative or indexical modes of acquaintance with the res, and ordinary epistemically weak or purely denotational de re ascriptions (MIE, ch. 8, §5; AR, p. 172), but that is another story I tell elsewhere (Crawford 2008).

6 Here it is worth pointing out another difference with Quine. Brandom does not view ordinary (weak, denotational) de re ascriptions as ontologically committing the ascriber to the existence of the res, though he does view special epistemically strong ones as existentially committing. See note 2 above. Unfortunately, Brandom does not discuss the kind of quantified de re ascriptions that initially interested Quine and that he originally dubbed relational and with whose hybrid perspectivality he was most concerned, such as 'There is someone whom Ralph believes to be a spy'/'Ralph believes, of someone, that he is a spy'. Again, to my ear, both of these-with and without the anaphoric structure (see note 1 above)-sound ontologically committing. Brandom's 
But the attributing-and-undertaking feature present in de re ascriptions is more interesting and important to mutual understanding and communicationand is the aspect of Brandom's inferentialism that purports to recover the representational dimension of propositional content. For de re ascriptions report what, from the ascriber's point of view, the believer's belief is about, thereby enabling the ascriber to determine whether, by his lights, what the believer believes is true. If I do not know anything about the inventor of bifocals (maybe I do not even know what a bifocal is) then I am not in a position to assess whether Adams's belief as reported in DD is true. But if someone tells me, say, that Franklin is the inventor of bifocals (something, as we supposed previously, that Adams may not know or may even deny), then I can form the de re ascription:

Adams believes, of Franklin, that he did not invent the lightening rod,

and thereby say ("like an actor stepping out of his part") of whom Adams holds his belief, that is, who his belief is about, who it represents as not having invented the lightening rod. If I also happen to think that I know that Franklin did in fact invent the lightening rod, then my breaching of the barrier between my and Adams's worlds enables me to assess Adams's claim as (by my lights) false, that is, as a claim that is false of Franklin. Here, in addition to attributing a commitment to Adams with the de dicto 'that'-clause portion, namely, that he believes someone did not invent the lightening rod, a commitment (or at least a known implication of a commitment) that Adams acknowledges, I undertake, in the de re 'of' portion, a commitment about who this belief of Adams's is about, namely, that it is a belief about Franklin, which is a commitment that Adams himself may not acknowledge and may even deny. So Brandom speaks of the "de re or undertaking position" and the "de dicto or attributing position" of de re ascriptions (MIE, p. 516), concluding that "the marking of portions of the content-specification of a propositional attitude ascription into de dicto and de re portions makes explicit the essential deontic scorekeeping distinction of social perspective between commitments attributed and those undertaken" (AR, p. 178). ${ }^{7}$

failure to discuss quantified de re attitude ascriptions-a notable lacunae in his account-is partly owed, I think, to his conflation (in MIE, p. 548) of the de dicto/de re distinction with Quine's distinction between relational and notional belief (a common conflation exposed in Crawford 2008).

7 In Brandom's later work Tales of the Mighty Dead (2002) this deontic score-keeping account of de dicto and de re specifications of conceptual content is carried over (with a further species of de traditione ascription) into the Gadamerian hermeneutic enterprise of dialogically interpreting historical philosophical texts, though that extension will not concern us here, as it does not directly concern action. Brandom's conception of the de re/de dicto distinction also appears in his 


\section{Action Explanation}

With this framework behind us, let us now turn to the explanation and assessment of intentional action. Brandom's basic idea here is that "de dicto and de re ascriptions underwrite two different kinds of intentional explanation" (MIE, p. 522; cf. Crawford 2012). De dicto ascriptions ascribe contents from the perspective of the agent and so are thereby able to rationalize (in Davidson's 1980 sense) actions. In Brandomese, de dicto ascriptions state the agent's commitments, doxastic and otherwise, in a way that he or she would acknowledge and recognize as forming part or all of his or her reasons for performing an action. Accordingly, de dicto ascriptions are suited to explain what an agent is trying to do, in a sense that he would acknowledge as what he is trying to do. De re ascriptions, on the other hand, as we have seen, ascribe contents from the point of view of the ascriber, and express the ascriber's commitments, which are not necessarily attributed by the ascriber to the agent of the ascription. De re ascriptions, accordingly, explain why actions turn out as they do, what an agent actually does, from the ascriber's perspective-and these are actions under descriptions which the agent may not recognize as descriptions of his or her actions and therefore for which he or she may not have reasons for performing. We might put it this way. Rationalising psychological explanations explain actions under descriptions under which they are intentional-and it seems apt to call such actions tryings, for they are what the agent is trying, attempting, intending to do, or aiming at. These are the kinds of explanations that wholly invoke agents' reasons, and hence, the de dicto attribution of beliefs, desires and intentions. There are also psychological explanations for actions under descriptions under which they are not intentional; such explanations do not wholly invoke agents' reasons for doing what they do, so it seems apt to call such actions doings, because they are still actions, just not intentional ones. Summing up, in my own Brandomian terminology, de dicto ascriptions explain tryings and de re ascriptions explain doings. Accordingly, we can speak of de dicto and de re explanation of action. ${ }^{8}$

recent $A$ Spirit of Trust. A Reading of Hegel's Phenomenology (Brandom 2019, passim), where it is sometimes applied to certain kinds of actions, but again these applications to specifically Hegelian themes are not relevant here.

8 This brief account of de dicto and de re explanation of action, and the distinction between tryings and doings, is set out in much greater detail in Crawford (2012). It is important to note, however, that there can be, in a perfectly legitimate sense of 'try', de re ascriptions of what agents' try to do. See note 9 below for further discussion. 
Taking one of Brandom's own examples as an illustration, we may seek to explain why Nicole shot the animal in front of her. The explanation (somewhat elliptical) might be: she wanted to shoot a deer and believed (de dicto) that the animal in front of her was a deer. This ascription specifies the conceptual content of Nicole's belief from her perspective, that is, in a way that she would acknowledge as something that she is committed to. Alas, we can well imagine that, as luck would have it, the animal in front of her was unfortunately not a deer but a cow, so that, as Brandom says, "Shooting a deer is something she was trying to do but failed" (MIE, p. 524). Although she succeeded in shooting the animal in front of her, she failed to do what she ultimately wanted or aimed to do by shooting the animal in front of her, namely, shoot a deer; what she actually did, what she ended up doing by shooting the animal in front of her, was shoot a cow. Her shooting the animal in front of her had the unintended consequence that she shot a cow, and as Brandom has reminded us (MIE, p. 523) of what Davidson (1980) reminded us of, our actions can be re-described in terms of their unintended consequences. So Nicole did shoot a cow. Now, given that she wanted to shoot a deer, why did she end up shooting a cow? We can't explain this action of hers wholly in terms of her own acknowledged doxastic and practical commitments, wholly in de dicto terms, because it was not something she was trying to do, that she was aiming at, that she had reason to do. The only way to explain this action of hers is to ascribe to her a belief in the de re style and to say that she (mistakenly) believed, of the cow that she shot, that it was a deer. As Brandom puts it "That Nicole's belief that the animal in front of her was a deer was a belief of a cow that it was a deer in front of her is just what is needed to explain why Nicole shot a cow" (MIE, pp. 523-24). ${ }^{9}$

9 As mentioned in note 8, it is of course perfectly acceptable to say, in a de re attribution, that Nicole tried to shoot a cow (because she thought it was a deer), or that a cow was such that Nicole tried to shoot it (cf. 'Can you believe it? Oedipus tried to marry his own mother!'). These are (true) de re ascriptions of what Nicole was trying (or attempting) to do from the point of view of those who are "in the know" (though they do not take exactly Brandom's canonical form), but they are not descriptions of Nicole's trying, in my Brandomian technical sense, which would require a de dicto ascription. One might say that tryings in the technical sense, for which de dicto explanations are necessary, are the ways agents self-consciously represent the aim of their action to themselves. (I am grateful to an anonymous reviewer for suggesting this way of putting it and for helpful comments pressing me to clarify this issue.) We can call these de dicto tryings. Of course, what agents try to do, in this sense, that is, de dicto tryings, can be re-described in ways that agents do not recognize as representing their aim or in ways that show that their represented aim cannot in fact be met by doing what they are doing, as in the case of Nicole (and Oedipus)-or a time traveler unknowingly trying (de re) to kill his younger self. Cf. the distinction between de dicto and de re tryings drawn by Smith (1997, pp. 379-80) in the context of a discussion of time travel. 


\section{De re Explanation: The Problem of Near Contraries}

De re explanation has, however, been widely denigrated by philosophers (see, e.g., Boghossian 1994; Carruthers 1988; Dennett 1982; Fodor 1980; Grandy 1986; Lycan 1985; Schiffer 1978, but especially Baker 1982), although Brandom nowhere registers this. ${ }^{10}$ The problem with de re ascriptions is supposed to be that, while de dicto ascriptions are bound by normative principles of rationality (emphasized and argued for most famously by Davidson 1980, 1984 and Dennett 1987), which proscribe the attribution of inconsistent contents (at least ceteris paribus), de re ascriptions regularly violate them, and therefore, unlike de dicto ascriptions, license the attribution of inconsistent contents (Baker 1982; Dennett 1982; Quine 1956). That de dicto ascriptions are attributed on the basis of the so-called "assumption of rationality" is clear from the fact that in order for de dicto ascriptions to be true of a believer, he must acknowledge commitment to their 'that'-clauses and no sincere and competent language user who understands a series of sentences (and who is not tired, ill, distracted, intoxicated or otherwise incapacitated) accepts them if they are inconsistent (and not too long and complicated). The "assumption of rationality" governing de dicto ascriptions of belief arguably derives from the fact that speaking logically is part of what it is to speak competently (Crawford 2012). As Quine says, "we learn logic in learning language" Quine (1986, p. 100). Since the only de dicto ascriptions of belief that can be true of an individual are those whose content clauses correspond to the sentences he accepts qua competent speaker of a language, and being a competent speaker of a language means by and large abiding by basic rules of logic, the only de dicto ascriptions that can be true of an individual are those whose content clauses conform to the basic rules of logic.

That things are very different with de re ascriptions is made evident by Quine in the rest of the passage quoted above:

He [the ascriber] says there is someone whom Ralph believes to be a spy; someone in the ascriber's real world, irrespective of how Ralph's attitudinal world may be populated. He declares that

$\exists \mathrm{x}($ Ralph believes that $\mathrm{x}$ is a spy),

thus affirming the existence, in the real world, of a suspect in Ralph's world. How the crossidentification? Maybe there are two people whom Ralph has taken to be one. Maybe there is one whom he has taken to be two, suspecting the one while trusting the other. A virtue of our

10 I discuss Baker's challenging argument in detail and defend de re explanation against it in Crawford (2021). 
[linguisticized de dicto] treatment was that it sealed off the two worlds, obviating such collision of incompatible ontologies" (loc. cit.).

As we have seen, it is precisely the seamlessness of de re ascriptions, with their cross-identification, that is so fundamental for Brandom. But, as Quine notes, this seamlessness makes de re ascribers' cross-identifications subject to ontological collision, which brings in its wake inconsistency on the part of the attitudinist. The latter type of collision-taking one thing to be two-is in fact the situation in Quine's original story of Ralph and Ortcutt. According to it, the following de dicto ascriptions are true:

(1) Ralph believes that the man in the brown hat is a spy

(2) Ralph believes that the man at the beach is not a spy

(3) Ralph believes that the man at the beach is a pillar of the community.

This is because Ralph would acknowledge his commitment to the truth of the three 'that'-clauses. The ascriber-cum-deontic-score-keeper, however, is committed to the identity:

the man in the brown hat = the man at the beach = Ortcutt,

which Ralph would not acknowledge as a commitment. Together with (1) and (2), the identity brings with it various substitution-inferential commitments on the part of the ascriber-score keeper, which include the de re ascriptions:

(4) Ralph believes, of Ortcutt, that he is a spy

(5) Ralph believes, of Ortcutt, that he is not a spy.

Brandom, of course, is perfectly aware of this feature of de re ascriptions. In MIE he notes at one point, in passing, that "Certainly in the de re sense, one can believe of Benjamin Franklin, as the inventor of bifocals, that he did not invent the lightning rod, and also believe of Benjamin Franklin, as the inventor of the lightning rod, that he did invent the lightning rod” (p. 576). But he fails to note that this poses a potential threat to the role that he wants to give de re ascriptions in the explanation of doings.

Quine (1956) originally called such de re ascriptive collisions, in which someone believes of $a$, that it is $F$ and believes of $a$ that it is not $F$, "near contraries." In such cases, we have a single object to which a person unknowingly predicates two incompatible properties. In the above quotation, Quine mentions a second kind of $d e$ re collision, one that involves two (or more) objects to each of which a person unknowingly predicates, inconsistently, a single uniquely instantiated property. 
Examples of this kind of collision (see Baker 1982; Crawford 2021; Dennett 1987) can involve an individual who thinks, of one thing $a$, that it is the only $F$, and thinks of another thing $b$ (where $a \neq b$ ), that it is the only $F$. Another type of case is where a person thinks of $a$, that it is the more $F$ or the most $F$, and thinks of $b$ (where $a \neq b$ ), that it is the more $F$ or the most $F$, where $F$ is an adjective such as 'beautiful' or 'valuable'. The presence of these ontological collisions in the perspectivally hybrid de re idiom is seen by its detractors as displaying so much confusion on the part of the attitudinist-even if it is entirely rational confusion-that it renders de re ascriptions unsuitable for the explanation and prediction of action.

Here I will only consider the first type of near contrary where someone mistakes one thing for two, an example of which is of course Ralph and Ortcutt. ${ }^{11}$ Suppose Ralph, a fanatical patriot, tries to shoot the man in the brown hat because he wants (de dicto) to kill a spy and believes (de dicto) that the man in the brown hat is a spy. Now Ralph also wants (de dicto) not to shoot Ortcutt, because he thinks (de dicto) that he is pillar of the community. But, according to our ontological commitments, Ortcutt is the man in the brown hat and so we may wish to explain why Ralph shot Ortcutt. According to Brandom, the explanation is that Ralph believed, of Ortcutt, that he was a spy. The same de re ascription presumably must be used by an ascriber to predict that Ralph will shoot Ortcutt. The alleged problem with this is that Ralph also believed, of Ortcutt, that he was not a spy. As soon as we dissociate our ascription from the denizens of Ralph's ontology and train it upon those of ours, and indulge in cross-identification, as we do with de re ascriptions, we run up against the fact that Ralph has inconsistent attitudes towards the things he acts on. How can our de re attribution to Ralph, of the belief, of Ortcutt, that he is a spy, explain Ralph's shooting him-or enable us to predict that he will shoot himwhen we're also committed to the claim that he also believes, of him, that he is not a spy?

Shifting from assassination to hunting, it is an easy matter to put Nicole in a similar situation, in which she not only believes, of the cow she shot, that it is a deer, but also believes, of that same cow, that it is not a deer, perhaps because it is her cow and she (obviously) believes (de dicto) that her cow is not a deer. But, then, how can her belief of it that it is a deer explain her shooting it, as Brandom claims it does-or enable us to predict that she will shoot it-when she also believes of it that it is not a deer? Notice too that Ralph and Nicole will have, from the de re scorekeeper's point of view, all sorts of inconsistent intentions and desires. Ralph, for

11 I discuss the other type of near contrary case, where two objects are mistaken for one, in the general context of action explanation, in Crawford 2021, where the solution proposed below is shown to apply to it too. 
example, will intend, of the man in the brown hat, that he shoot him. But he will also intend, of the man in the brown hat, that he not shoot him (because he intends de dicto not to shoot Ortcutt the pillar). Nicole will intend of the cow, that she shoot it. But she may well also intend, of the cow, that she not shoot it (because the cow is hers and she intends (de dicto) not to shoot her own $\operatorname{cow}^{12}$ ). By flouting the assumption of rationality that governs de dicto ascriptions, de re ascriptions make a mess of the believer's cognitive life and therefore the explanation and prediction of their behavior seemingly impossible. At least so argue the de re denigrators, who press hard this objection from near contraries. It turns out, however, that they are hoist on their own petard, for it is, ironically, the very logical laxity of the de re idiom that is the key to answering the objection.

\section{The Solution: De re Logical Fragmentation Implies Explanatory Independence}

To see this, we need to note a crucial feature of de re ascriptions that Quine (1956) took pains to point out in his original discussion, something that Brandom fails to mention. Quine noted that (4) and (5) do not make Ralph out to be irrational because they do not entail

(6) Ralph believes, of Ortcutt, that he is a spy and he is not a spy.

Although he does not discuss the issue (so far as I am aware) Brandom would certainly agree with Quine about this. For in order for (6) to be true, Ralph would have to be committed to the truth of the de dicto 'that'-clause portion and so assent to the sentence 'he is a spy and he is not a spy' taking both pronouns to co-referand Ralph obviously does not do this. To put it another way, since, in Brandom's words, "behind every de re ascription there must be a de dicto ascription," and there is not one in this case, (6) cannot be true. Generally speaking, according to Brandom, any ascriber committed to the claim that $S$ believes of $t$ that $\phi$ (it), is committed to there being some $t^{\prime}$ such that $t=t^{\prime}$ and $S$ believes that $\phi\left(t^{\prime}\right)$. Since Ralph is by hypothesis rational and no rational person believes that $\phi(t) \& \sim \phi(t)$, (6) cannot be true.

We need not rely on examples involving inconsistent beliefs. For it is clear in Ralph's case that although

12 Maybe it is a dairy cow. 
(7) Ralph believes, of Ortcutt, that he is the man at the beach.

and

(8) Ralph believes, of Ortcutt, that he is the man in the brown hat.

are both true (by our lights) it is not true that

(9) Ralph believes, of Ortcutt, that he is the man at the beach and the man in the brown hat.

For imagine that someone tells Ralph that the man he saw at the beach is the man he saw in the brown hat. This should be shocking news to Ralph. But if (9) is already true because (7) and (8) are true then it cannot be news at all to Ralph. Since the details of Quine's story license (7) and (8), and the subjunctive that if Ralph were to become apprised of the fact that the sentence 'The man is the brown hat is the man at the beach' is true, then he would learn something new, (9) cannot be true. ${ }^{13}$

Generally speaking, we can say that a commitment to the claims that $S$ believes, of $t$, that it is $\phi$, and that $S$ believes, of $t$, that it is $\psi$, does not bring with it a commitment to the claim that $S$ believes, of $t$, that it is both $\phi$ and $\psi$. The de re idiom, we might say, violates Doxastic Conjunction Introduction (DCI). The de dicto idiom, on the other hand, arguably abides by DCI. S's believing that $t$ is $\phi$ and $S$ 's believing that $t$ is $\psi$ would seem to imply that $S$ believes that $t$ is $\phi$ and $\psi$. After all, the truth of the de dicto ascriptions, $S$ believes that $t$ is $\phi$ and $S$ believes that $t$ is $\psi$, is a sufficient condition for $S$ 's accepting sentences of the form $\ulcorner t$ is $\phi\urcorner$ and $\ulcorner t$ is $\psi\urcorner$. But if $S$ accepts-or is disposed to accept-the sentences $\ulcorner t$ is $\phi\urcorner$ and $\ulcorner t$ is $\psi\urcorner$ then it is hard to see how $S$ could fail to accept-or fail to be disposed to accept-the sentence $\ulcorner t$ is $\phi$ and $\psi\urcorner$, after due consideration of it, so long as $S$ understands both occurrences of $\ulcorner t\urcorner$ to co-refer and is a competent speaker of the language (understands, for example, what 'and' means) and is not tired, ill, distracted, and so on.

The failure of DCI means, I submit, that near contrary de re ascriptions, such as (4) and (5), stand logically fragmented-or compartmentalised or partitioned-from each other, and hence, are explanatorily independent, that is, can be legitimately employed separately in different explanatory contexts despite being simultaneously true in all contexts. De re detractors abstract de re ascriptions from the contexts in which they become true and thereby fail to distinguish which among them is explanatorily relevant to the context of action at hand.

The de re ascriptions (4) and (5) become true-i.e., the beliefs reported are formed-in two different contexts or circumstances: one in which Ortcutt is presented to Ralph as the man in the brown hat and one in which he is presented as Ortcutt the grey-haired pillar at the beach. Ralph performs his shooting in only one

13 Cf. Dummett 1978, 1975 (Appendix). 
of these contexts, namely, the former. The ascriber can use (4) to explain (and predict) Ralph's shooting Ortcutt because he knows that the context of belief formation, in which (4) became true, is the same as the context of action in which Ralph's shooting is taking place. Indeed, all the various cases of mistaken identity that have paraded through the philosophical literature that appear to confound de re explanation-Ralph and Ortcutt, Hesperus and Phosphorus, Superman and Clark Kent, $\mathrm{H}_{2} \mathrm{O}$ and XYZ, etc.-turn on the protagonists not recognizing something as something they believe to have a certain property because of a disparity between the original context of belief fixation in which the de re ascriptions true of them became true of them and the new context of their subsequent actions. This indicates that the reason why we know just what these protagonists are going to do, and so can explain their doings with de re ascriptions, must have something essentially to do with our knowledge of the context of belief formation in which the de re ascriptions became true and the context in which their subsequent actions are taking place, and the relation between them.

In short, the answer to the question of how Ralph's belief, of Ortcutt, that he is a spy, can explain his shooting him if he also believes, of Ortcutt, that he is not a spy, is that (4) is relevant to an explanation of Ralph's shooting Ortcutt in a context in which the latter is wearing the brown hat because it became true-i.e., the belief reported was formed-in a context in which Ortcutt was wearing the brown hat. The fact that (5) is also true of Ralph in that context-even as he is shooting Ortcutt -has no bearing on an explanation of Ralph's action because (5) did not become true (the belief reported was not formed) in a context in which Ortcutt was wearing the brown hat. Since (5) became true (the belief reported was formed) in a context in which Ortcutt was presented to Ralph as the man at the beach, it is not relevant to an explanation of his shooting Ortcutt in a context in which Ortcutt is wearing the brown hat. The same applies, mutatis mutandis, to my Quinean "near contrary" version of Brandom's story of Nicole and her cow. ${ }^{14}$

We can make more precise the idea that it is the relation between contexts of action and contexts of belief formation that renders some de re ascriptions explanatorily relevant and others explanatorily irrelevant by drawing on Sosa and Pastin's (1981) concepts of motivating and locating properties. Speaking de dicto, Ralph believes that the suspicious man in the brown hat is a spy. He says as much. Indeed, he says more: he says that the next time he sees the suspicious man in the brown hat he will shoot him. So, the property of Ortcutt that motivates Ralph to shoot him is the having-the-suspicious-man-in-the-brown-hat appearance. This is not enough actually to get Ralph to shoot Ortcutt, however. He also needs to locate Ortcutt on the basis of that motivating property. After all, there is Ralph talking to

14 I leave this as an exercise for the reader. 
Ortcutt on the beach and telling him that the next time he sees the man in the brown hat he is going to shoot him. Ralph's problem is that he is motivated to shoot Ortcutt on the basis of a property that does not locate Ortcutt for him. When he is talking to Ortcutt on the beach the property that locates Ortcutt for him is havingthe-man-at-the-beach appearance. So there is a property of Ortcutt that motivates Ralph to shoot him, and a property of Ortcutt that locates him for him to shoot, but the properties are not the same; nor are they connected by Ralph to the same individual, that is, to Ortcutt. For Ralph to shoot Ortcutt, there needs to be either a single property of Ortcutt that both motivates Ralph to shoot him and that locates him for shooting (e.g., having-the-suspicious-man-in-the-brown-hat appearance), or separate motivating and locating properties or near correlates of them (e.g., having-the-suspicious-man-in-the-brown-hat appearance and having-the-man-atthe-beach appearance-or simply being-the-suspicious-man-in-the-brown-hat and being-the-man-at-the-beach) need to be connected by Ralph to Ortcutt. ${ }^{15}$ So far in the story, Ralph will shoot Ortcutt only when he sees him acting suspiciously in the brown hat because only this property both motivates and locates Ortcutt for him to shoot. So he will not shoot him at the beach. But, were Ralph to become apprised-either through tracking Orcutt's movements from the sensitive installation to the beach while witnessing his change of clothes, or by way of others' testimony, or perhaps by way of his own memory-that the man in the brown hat is the man at the beach, then he would shoot Ortcutt at the beach. This is because, although the property that motivates him to shoot Ortcutt (being-the-suspiciousman-in-the-brown-hat) is not the same property that locates him for shooting (being-the-man-at-the-beach) Ortcutt would at that time be believed by him to have the conjunctive property of being-the-suspicious-man-in-the-brown-hatand-the-man-at-the-beach. In this situation, he will shoot Ortcutt at the beach on the basis of a motivating property that is distinct from a locating property because the two have become connected in his mind with the same individual.

The idea of a motivating property is another way of describing the relevance of the context of belief fixation to action on the basis of belief; the idea of a locating property is another way of describing the relevance of the context of action to action on the basis of belief. For an agent to act on an object at a certain time that object must present some property to the agent that both locates the object for him to act on at that time and motivates him to act on it at that time (or different locating and motivating properties must be connected by the agent to the object in question at the time of action via identity judgements formed through tracking, testimony,

15 I am here again indebted to the aforementioned anonymous reviewer for insightful comments that prompted the more explicit addition of the second disjunct as sufficient for action. 
recognition or memory). A property of an object becomes a motivating property in the context of belief formation. This is what has happened with Ralph: it is with the advent of (4) that having-the-suspicious-man-in-the-brown-hat appearance becomes a motivating property for Ralph. If this motivating property is to lead Ralph to shoot Ortcutt then it must also be a locating property (or become connected with one). It is when this motivating property becomes a locating property (or connected with one) that action occurs and Ralph shoots Ortcutt. When the context of action is one in which Ortcutt is wearing a brown hat and skulking around a sensitive installation, then of the two locating properties, having-the-suspicious-man-inthe-brown-hat appearance and having-the-man-in-at-the-beach appearance, only the former is also a motivating property (and the properties are not connected). So only (4) is relevant to an explanation of Ralph's shooting.

One question that remains, however, is how to individuate the "contexts" to which appeal has been made, together with the logical fragmentation of de re belief ascriptions, to solve the problem of near contraries. I have said that the reason why Ralph does not shoot Ortcutt when he sees him at the beach-even though he believes, of him, that he is a spy-is that this context of action is different from the context of belief formation in which the de re ascription that he believes, of Ortrcutt, that he is a spy, becomes true. But on what ground can I claim this? What explains why this is a different context, other than the fact that he does not shoot Ortcutt in it-which is the very thing to be explained? The answer, I suggest, lies in the fact that Ralph has lost track of Ortcutt: he loses track of him between the time when he sees him in the brown hat and the time when he sees him at the beach. So contexts are to be individuated by appeal to the (philosophically speaking, primitive) notion of keeping track of an object through space and time. A subject moves into a different context with respect to an object when he loses track of that object, that is, fails continuously to perceive or otherwise know about (through recognition, testimony or memory, for example) the object's change of location and/or appearance. ${ }^{16}$ Ralph might have perceptually tracked Ortcutt throughout the period in which his appearance changed from being a suspicious man in a brown hat to being a pillar at the beach. In such a situation the context of action and the context of belief formation would be one and the same and so Ralph would have shot Ortcutt when he saw him at the beach. To put it in terms of the notion of a motivating property, if Ralph had kept track of Ortcutt by perceiving his changes in appearance and location, then another property of Ortcutt would have become a motivating property for Ralph, namely, having-the-pillar-at-the-beach-

16 See Evans $(1981,1982)$ for more extensive discussion about how spatial and temporal tracking figures in information-based thought, a discussion which is not only congenial to the treatment given here but was the inspiration for the appeal to tracking as a way of individuating contexts. 
appearance. In this situation Ralph would have shot Ortcutt at the beach and so his context of action and his context of belief formation would not have diverged in the way they did in Quine's original story. The same applies, mutatis mutandis, to Brandom's Nicole and her cow.

Acknowledgment: This paper was presented at the conference Themes from the Philosophy of Robert Brandom at Marquette University on 23 February 2019. I'm grateful to the participants for helpful discussion, especially Robert Brandom. I also thank the conference organizers Sebastian Luft, Corinne Bloch-Mullins, and Yoon Choi for their warm hospitality in a very cold Milwaukee! An ancient debt is owed to Rowland Stout for inviting me and other graduate students to his reading group on Marking it Explicit at Oriel College, Oxford sometime in the late 1990s.

\section{References}

Baker, L. R. 1982. “De Re Belief in Action.” The Philosophical Review 91: 363-87.

Boghossian, P. A. 1994. "The Transparency of Mental Content." Philosophical Perspectives 8: 33-50.

Brandom, R. 1994. Making it Explicit. Reasoning, Representing and Discursive Commitment. Harvard: Harvard University Press.

Brandom, R. 2000. Articulating Reasons. An Introduction to Inferentialism. Harvard: Harvard University Press.

Brandom, R. 2002. Tales of the Mighty Dead. Harvard: Harvard University Press.

Brandom, R. 2019. A Spirit of Trust. A Reading of Hegel's Phenomenology. Harvard: Harvard University Press.

Crawford, S. 2008. "Quantifiers and Propositional Attitudes: Quine Revisited." Synthese 160: 75-96.

Crawford, S. 2012. "De Re and De Dicto Explanation of Action." Philosophia 40: 783-98.

Crawford, S. 2021. "De Re Explanation of Action in Context, the Problem of "Near Contraries", and Belief Fragmentation." In Context Dependence in Language, Action and Cognition, edited by P. Grabarczyk, and T. Ciercierski. Berlin: DeGruyter.

Carruthers, P. 1988. “More Faith Than Hope: Russellian Thoughts Attacked.” Analysis 48: 91-6. Davidson, D. 1980. Essays on Actions and Events. Oxford: Clarendon Press.

Davidson, D. 1984. Inquiries into Truth and Interpretation. Oxford: Clarendon Press.

Dennett, D. 1982. “Beyond Belief." In Thought and Object, edited by A. Woodfield. Oxford: Clarendon Press. Repr. in Dennett 1987.

Dennett, D. 1987. The Intentional Stance. Cambridge, Mass: MIT Press.

Dummett, M. 1975. "What is a Theory of Meaning?." In Mind and Language, edited by

S. Guttenplan. Oxford: Clarendon Press.

Dummett, M. 1978. "Frege's Distinction Between Sense and Reference." In Truth and Other Enigmas. London: Duckworth.

Evans, G. 1981. "Understanding Demonstratives." In Meaning and Understanding, edited by H. Parret, and J. Bouveresse. Berlin: de Gruyter. 
Evans, G. 1982. The Varieties of Reference, edited by J. McDowell. Oxford: Clarendon Press. Fodor, J. 1980. "Methodological Solipsism Considered as a Research Strategy in Cognitive Psychology." The Behavioural and Brain Sciences 3: 63-73.

Forbes, G. 1996. "Substitutivity and the Coherence of Quantifying In." Philosophical Review 105: 337-72.

Grandy, R. 1986. "Some Misconceptions about Belief." In Philosophical Grounds of Rationality, edited by R. Grandy, and R. Warner. Oxford: Clarendon Press.

Kaplan, D. 1968. "Quantifying In.” Synthese 19: 178-214.

Kaplan, D. 1986. "Opacity.” In The Philosophy of W. V. Quine. La Salle, edited by L. E.Hahn, and A. S. Paul. Illinois: Open Court.

Lycan, William. 1985. "Thoughts about Things." In The Representation of Knowledge and Belief, edited by M. Brand, and R.M. Harnish. Tucson: University of Arizona Press.

Quine, W. V. 1956. “Quantifiers and Propositional Attitudes.” Journal of Philosophy 53: 177-87. Quine, W. V. 1986. Philosophy of Logic, 2nd ed.: Harvard University Press.

Quine, W. V. 1986a. "Reply to David Kaplan.” In The Philosophy of W. V. Quine. La Salle, edited by L. E.Hahn, and A. S. Paul. Illinois: Open Court.

Quine, W. V. 1990. Pursuit of Truth. Harvard: Harvard University Press, Rev'd ed. 1992.

Quine, W. V. 1995. From Stimulus to Science. Harvard: Harvard University Press.

Schiffer, S. 1978. "The Basis of Reference." Erkenntnis 13: 171-206.

Smith, N. J. J. 1997. "Bananas Enough for Time Travel?." The British Journal for the Philosophy of Science 48 (3): 363-89.

Sosa, E., and M. Pastin. 1981. "A Rejoinder on Actions and De Re Belief." Canadian Journal of Philosophy 11: 735-9. 